\title{
Enhancement of Higher Education Teaching of English in Saudi Arabia
}

\author{
Tahany Abdulaziz Albaiz \\ University of Jeddah, Jeddah, Kingdom of Saudi Arabia
}

\begin{abstract}
The research focused on the use of peer-observation of learning and teaching (POLT) as an approach to evaluating the teaching of English in institutions of higher education in Saudi Arabia. The existing literature has supported the relevance of POLT as a new approach to ensuring quality assurance and improving student-learning outcomes. The research involved 107 respondents who had different qualifications as teachers of English in institutions of higher education in Kingdom of Saudi Arabia. The study revealed an overwhelming support for the approach in terms of improving the quality of English learning in the country. The implementation of the approach requires the support of the accreditation bodies in the country, as well as the involvement of respective universities and collaboration with teachers for the best learning and teaching outcomes.
\end{abstract}

Keywords: English as a Foreign Language (EFL), teaching, evaluation, peer-observation, performance

\section{Introduction}

Saudi Arabia is the largest country in the Middle East. It shares borders with Kuwait, Iraq, Jordan, Yemen, Oman, Qatar, and the United Arab Emirates (Liton, 2013). The country had a population of approximately 26 million as of 2014 where the expatriates made up to $30 \%$ of the whole population (Moskovsky \& Alrabai, 2009). With an annual budget of approximately USD $\$ 300$ billion; the country is also the richest in Middle East because of its large crude oil resources where it accounts for $25 \%$ of all petroleum reserves in the world.

The Saudi educational system is very recent. It was established in 1924, consisting of only few primary schools for boys. In 1938, the Directorate of Education took over the control of private schools (Darandari et al., 2009). After the Second World War, the country's founder King Abdul-Aziz Al-Saud embarked on an initiative of creating an extensive educational framework that incorporated six years of primary education followed by three years of intermediate and three years of secondary school education (Liton, 2013). Initially, the education system only focused on the male child. However, in the 1960, females were officially allowed to enroll for education through gender-segregated schools (Al Shannag et al., 2013). Presently, the education system in Saudi Arabia is very elaborate, although segregation by gender continues.

The country's higher education sector is well established with 25 public universities and a growing number of private institutions of higher learning (Moskovsky \& Alrabai, 2009). The universities and other institutions of higher education offer a wide array of courses, such as engineering and medical services among others. Although religious studies are a major part of the education system, reforms in the education system

Tahany Abdulaziz Albaiz, Ed.D., associate professor, Faculty of Education, University of Jeddah. 
have allowed the Saudi Arabian higher education to become competitive as compared to other universities in the world (Al Shannag et al., 2013).

In a globalized world where English is used as an international language of communicating formally and informally, the teaching of English in Saudi Arabia has gained momentum in the country's higher education system (Moskovsky \& Alrabai, 2009). English is the only foreign language that is taught in Saudi Arabia, evidently showing the importance that the education sector places on the subject (Darling-Hammond, 2006). Across the world, the importance placed on English Language Teaching (ELT) as an international language has led to increased demands for exploring the teaching practices that pertain to the subject within the general education system (Darandari et al., 2009). The evaluation ELT is an important approach to quality assurance within the education system, specifically the teaching of the subject.

Teaching of English as an educational subject in Saudi Arabia was introduced in the 1930s. It was only used within the business setting following the discovery of oil in the country (Darandari et al., 2009). However, its syllabus was introduced in the 1950s where it was only taught in intermediate and secondary schools as a compulsory subject. However, education reforms introduced in 2010 now allow the subject to be taught to lower schools starting from Grade 4 when students are ten years of age (Al Shannag et al., 2013). The teachers of English language are mainly Saudis, although an increasing number of foreign teachers from Egypt, Jordan, and other neighboring regions are also present in the country.

Despite the importance and relevance of ELT as highlighted in the above objectives, there have been concerns that the teaching or learning is below the international standards that are expected for attaining adequate English language competency at each level of learning (Darling-Hammond et al., 2009; Light, Calkins, \& Cox, 2009). It is for this reason that calls have been made towards the enhancement of ELT throughout the education sector (Brown, 2011). One of the key areas of concern relate to the improper teaching of English language in higher education institutions due to laxity or ineffective quality assurance and evaluations methods that are in place. The main aim of this paper is to analyze the effectiveness and application of peer-observation of learning and teaching (POLT) of English language in higher education of Saudi Arabia.

\section{Theoretical Background}

The introduction of POLT follows the reflective practice model, which is a common theoretical framework that underpins various peer-observations teaching schemes (Chong \& Cheah, 2009). The reflective practice model entails the reconstruction of one's experience, a sincere acceptance and analysis of feedback report, and the evaluation of individual skills, knowledge, and attitudes (Kohut, Burnap, \& Yop, 2007). The model also provides room for the identification and exploration of new approaches to professional action. The reflective practice can be viewed as dialogue of thinking or doing, which allows one to become more skilled. According to Donnelly (2007), significant manifestation within the model encompasses three major elements, which consist of inquiring or reframing suppositions, considering substitute viewpoints, and appreciating that alterations in hypotheses amend meaning. Such a process leads to transformative learning, and hence, the need for reflection to be shared, as opposed to remaining a personal experience.

Reflective practice is important in the process of ensuring that teaching professionals gain central skills that guarantee that they can deliver high-quality content that can support the learning process for students (Darling-Hammond, 2006). The process is also an imperative approach that ensures that teachers are not isolated. It also ensures that teaching does not become routine and dull (Brown, 2011). The current reflective 
practice model incorporates a mentoring component where a wise and trusted advisor or counselor is involved in the POLT process (Bell \& Mladenovic, 2008). Through the mentoring approach, teachers gain an important academic professional development since the approach ensures the identification of potential and the fostering of talent (Darandari et al., 2009). Peers are invited to make observations and considerations on how the process of mentoring, coaching, or both can promote their teaching activities and professional development (Shortland, 2007). The peer-examination method persuades classmates to get insights into how they can employ training procedures to reinforce their perception and acquaintance to boost the eminence of students' scholarship results.

The effectiveness of POLT is further based on the theory of self-efficacy. According to Donnelly (2007), people have unique beliefs and perceptions about their efficacy in a given task. Different sources influence an individual's perception of his or her efficacy. Firstly, mastery experience is the most important influence on individual's efficacy beliefs (Minott \& Young, 2009). Mastery experience is molded through repeated performance of a given task until an individual develops a strong sense of self-efficacy. When a person has strong beliefs that his or her teaching has been successful, his or her self-efficacy increases (Coskun \& Daloglu, 2010). On the other hand, failure, especially when it happens in the early learning or teaching process, leads to a feeling of inadequacy, which consequently undermines an individual's sense of efficacy. The second influence on an individual's perception on self-efficacy is sensational experience with success or failure (Harford \& MacRuairc, 2008). Learning does not necessarily have to be through direct experience. As such, observation can play an important role in determining an individual's efficacy (Peacock, 2009). When a person observes another individual accomplishing a task, the positively influence he or she gains acts as a guide to self-efficacy.

\section{Literature Review}

\section{Quality Assurance in English Learning in Higher Education}

Quality assurance is a term that refers to the planned and systematic activities implemented to guide the development of services and products to meet specific standards and expectations (Chong \& Cheah, 2009). In the higher education sector, quality assurance indicates all measures and activities undertaken deliberately by institutions of education to meet explicit standards and prospects of customers or as guided by regulatory and accreditation bodies in the sector.

The importance or relevance of quality assurance approaches has been in existence since the industrial era in which the mass production of goods and services was controlled in such a way to maintain safety of such products (Altan, 2006). However, the application of quality management and quality assurance in higher education is a recent concept that has gained momentum in the 20th and 21 st centuries. Although early institutions of higher education had their standards of quality and considerable practices to maintain such standards, the introduction of quality assurance that touched on the industry at large was a new approach all together (Arnold, 2006). The efforts started with the establishment of governmental and non-governmental organizations whose main aim was to develop and examine various dimensions of higher education and/or provide relevant accreditations as dictated by the quality of standards that were found in the institutions (Ross \& Bruce, 2007).

In Saudi Arabia, the higher education sector is a recent one. Hence, the quality assurance segment is also very recent. However, the Higher Education Council established the National Commission for Academic Accreditation and Assessment (NCAAA) in 2004 (Darling-Hammond, 2010). The establishment of the 
commission was an initiative towards the improvement and standardization of higher education in the country to meet international standards (Martin \& Loomis, 2013). The main aim of the commission is to encourage and support the quality of higher education institution and programs offered by such institutions (Price et al., 2012). The role of the commission is divided into three areas, which include affirming the quality of student's learning outcomes, providing support services to higher education institutions, monitoring the efficiency of management in the institutions, and lastly determining the impact of the research and community development contributions of the higher education institutions (Marzano \& Toth, 2013). The NCAAA's mandate requires a close collaboration with the stakeholders, such as the higher education institutions, community agencies, and other institutions, such as the government and industries among others (Darling-Hammond, 2008). Despite the presence of NCAAA, there is low achievement and low levels of proficiency in the learning of English, which consequently indicates a challenge in the quality management in the teaching of English Language (Darling-Hammond, 2010).

\section{Challenges Facing the Learning of English in Saudi Arabia}

Despite the presence of NCAAA and other measures that have been put forward by the government to improve the outcomes of higher education English among students in institutions of higher education, positive results are yet to be achieved. Students' English proficiency is still below the expected standards and hence unsatisfactory (Alrashidi \& Phan, 2015). From the lower levels of education, students have low level of English competence, which they carry on to the universities (Berardo, 2006). One of the major weaknesses in the studying of English in schools in Saudi Arabia is the teacher-centered instruction where teachers rely on traditional teaching methods, which use Arabic to teach English while encouraging memorization as a primary strategy of learning (Al-Mekhlafi \& Nagaratnam, 2011). There is also the lack of motivation and encouragement from the teachers, lack of practical real-world example, and a prevailing assumption that English is a useless subject in the students' academic and social life. In the teacher-centered teaching approach, the student takes a passive role of observing and memorizing the information provided by the teacher, and hence, a major drawback that influences negatively the quality of higher education learning of English.

\section{The Use of POLT}

The use of peer-evaluation is an important evaluation and quality assurance approach that has gained momentum in the last few decades. Peer-observation of teaching as a method of quality assurance was first adopted in the early 1990s. It has since become a widespread practice in many institutions of higher learning in the world (Harvey \& Stensaker, 2008). The use of peer-observation of teaching is supported by research, because it ensures that teachers can reflect on the quality of their teaching, learning, and assessment practices. According to Fareh (2010), peer-observation leads to increase teachers' confidence, encourage debate, improve teachers' interaction with students, and leads to greater collegiality.

The effective use of peer-observation needs professional autonomy where the teacher being observed controls the observation process. Secondly, the main aim of the peer-observation is to stimulate self-evaluation and reflection (Darandari et al., 2009). The concept is a development process that promotes peer-learning among colleagues. The process requires a collaborative mutual trust and support. In addition, the peer-observation approach promotes dialogue, which consequently leads to the development of the individuals professionally (Brown, 2011). Above all, peer-observation should support up-to-date observation approaches to maintain the best outcomes. 
In the context of Saudi Arabia, peer-observation has not been applied in the teaching of English in higher education. In addition, since the existing evaluation and quality assurance measures towards the delivery of English learning have failed, it is important for new approaches to be considered to improve the outcomes of learning for students (Darling-Hammond et al., 2009). As discussed above, the use of peer-observation will promote dialogue and professional development of English teachers, thus ensuring better outcomes for English language students in Saudi Arabia (Harvey \& Stensaker, 2008). Further, it can provide an important opportunity for educators and related accreditation institution in the country to revise the quality assurance approaches in the country.

\section{Research Methodology}

\section{Research Context and Participants}

The study was conducted in Saudi Institutions of Higher Learning where English is taught as a foreign language. The participants of the study were university level English as a Foreign Language (EFL) teacher with a language teaching experience of more than two years. The participants were randomly selected to ensure fair representation throughout the targeted population. Only 107 teachers of English in higher institutions of learning were selected for the study. The number is ideal since it can be used to reveal important insights into higher education ETL in Saudi Arabia.

\section{Data Collection}

The data collection process involved the use of online survey questions that were send to participants through survey monkey. The survey contained 37 questions, which were adequate for revealing important insights and beliefs concerning the relevance and application of peer-observation as a way of improving the quality of learning outcomes for English language students in the country's higher education system. The survey constituted closed-ended questions to ensure that the participants gave concise responds, which would effectively show their opinions on different issues raised by the questionnaire. The choice of surveys was preferred because of its easy-to-use and non-intrusive nature, which grants the best opportunity for respondents to provide unbiased responses while maintaining their privacy.

\section{Results Analysis}

The analysis of the research data is an important part of research, which allows the conversion of raw data into meaningful information that can be used to generate trends and/or inform the findings of the study. In this section, the analysis of the collected data will use quantitative data analysis approaches where frequencies of responses from the survey questions will be represented through various methods of data representation, such as graphs, tables, and figures. Each data representation will be followed by a brief explanation to interpret the information.

The first question of the research sought to collect information on the qualifications of the teachers who responded to the survey in the research. Table 1 below shows that the level of qualification of the English language teachers who were engaged in the research:

Table 1 below shows that the teachers who were involved in the survey had a minimum qualification of a bachelor's degree. The teachers with bachelor's and master's degree qualification accounted for a combined share of $95 \%$ while those with doctorate qualification accounted for only $5 \%$. The higher number of teachers with bachelor's degree teaching in higher institutions of learning can be explained by the acute shortage of 
Saudi Arabian teachers who have a higher qualification and/or willing to teach English in universities. Overall, the respondents had the necessary qualifications to participate in the research.

Table 1

What is Your Degree in Teaching EFL?

\begin{tabular}{lcc}
\hline The level of qualification (Degree) & Number of respondents & Percentage (\%) \\
\hline Bachelor's degree & 51 & 50.5 \\
Master's degree & 45 & 44.5 \\
Doctorate degree & 5 & 5.0 \\
Total & 101 & 100.0 \\
\hline
\end{tabular}

\section{Teachers are comfortable when visitors are from the same discipline}

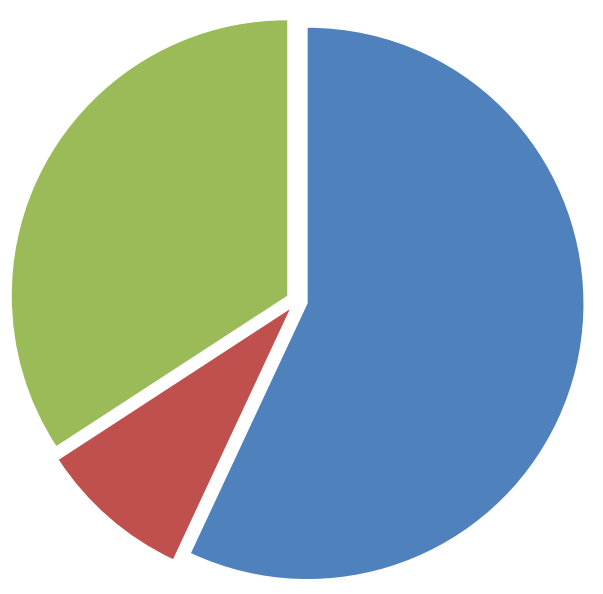

$\square$ Yes

$\square$ No

Maybe

Figure 1. Showing the comfort of teachers in presence of visitors from the same discipline.

The second survey question sought to know the number of years of experience that the participants had as teachers of EFL. The results revealed that out of the 105 responses obtained, $27.62 \%$ of the teachers had an experience of 1-3 years. Majority of the teachers, representing $45.71 \%$, had an experience of 4-10 years while the remaining $26.67 \%$ of the teachers had an experience of more than 10 years. Table 2 below is a summary of the information above:

Table 2

Years of Experience in Teaching EFL

\begin{tabular}{lcc}
\hline Experience (Years) & Number of respondents & Percentage (\%) \\
\hline $1-3$ & 29 & 27.62 \\
$4-10$ & 48 & 45.71 \\
+10 & 28 & 26.97 \\
Total & 105 & 100 \\
\hline
\end{tabular}

Teachers were also asked their views regarding their comfort in the presence of the visitors or peer-observers from their discipline. The results revealed, as in Figure 1, that teachers were more comfortable if the visitors were from their discipline as follows: 
The research also found that classroom visitation by colleagues was linked to improvement in the decision-making skills of the the teachers being evaluated. From the results, $46.15 \%$ of the respondents pointed out to the improved decision-making skills from evaluations by their peers or mentors. Table 3 below represents the responses as follows:

Table 3

Visitation Improves Decision Making Skills

\begin{tabular}{llc}
\hline Visitation improves decision making & Number of respondents & Percentage (\%) \\
\hline Yes & 36 & 46.15 \\
No & 18 & 23.08 \\
Maybe & 24 & 30.77 \\
Total & 78 & 100 \\
\hline
\end{tabular}

The survey required the respondents to indicate whether the expected visitation or peer-observation influenced their preparations for the expected teaching lesson. The results indicated a very small disparity between the responses that were provided, with $32.43 \%$ indicating that such visitation influenced their preparations. However, $39.19 \%$ indicated no difference in their preparations. The remaining $32.43 \%$ were not sure, an indication that their preparations were dependent on their opinions on the importance of the peer-observations. Figure 2 below represents the outcomes of the research question:

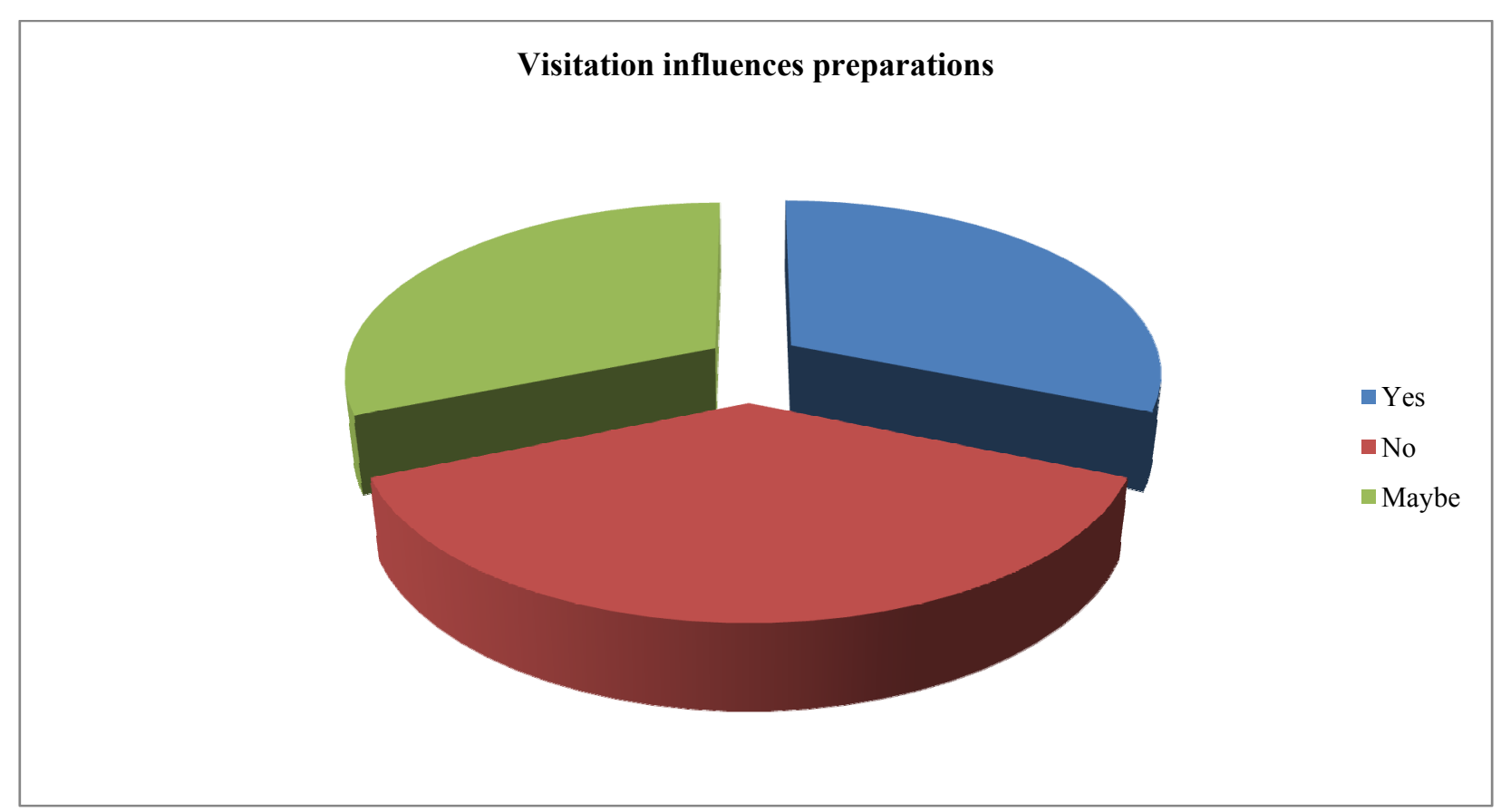

Figure 2. Influence of expected visitation on teacher preparation.

The survey revealed that most teachers did not view visitation by colleagues as a formal assessment process. Table 4 below shows the responses to the question:

About $62.34 \%$ of the respondents agreed with the statement, "Visitation by skilled and experienced colleagues can be extremely useful." However, 9.09\% did not think so, while the remaining $29.87 \%$ were not sure (see Figure 3). 
Table 4

Peer-Observation Is a Formal Assessment Process

\begin{tabular}{lll}
\hline Whether visitation is a & Number of respondents & Percentage (\%) \\
formal assessment process & 26 & 34.67 \\
Yes & 31 & 41.33 \\
No & 19 & 25.33 \\
Maybe & 76 & 100 \\
\hline
\end{tabular}

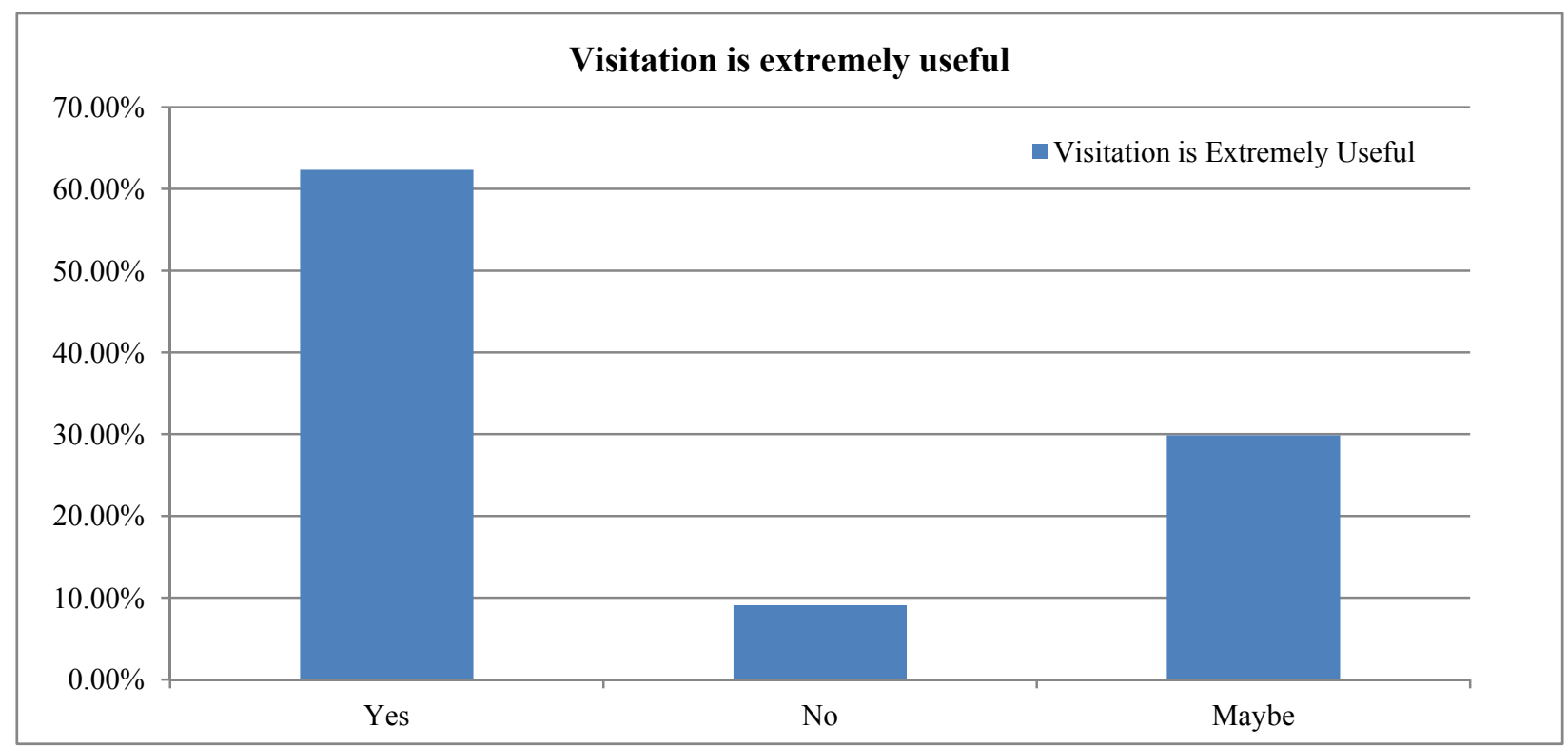

Figure 3. Visitation by experienced and skilled colleagues is helpful.

The respondents were also required to reveal whether they perceived that teacher visitation by colleagues improved teacher accountability. The results were as shown in Figure 4 below:

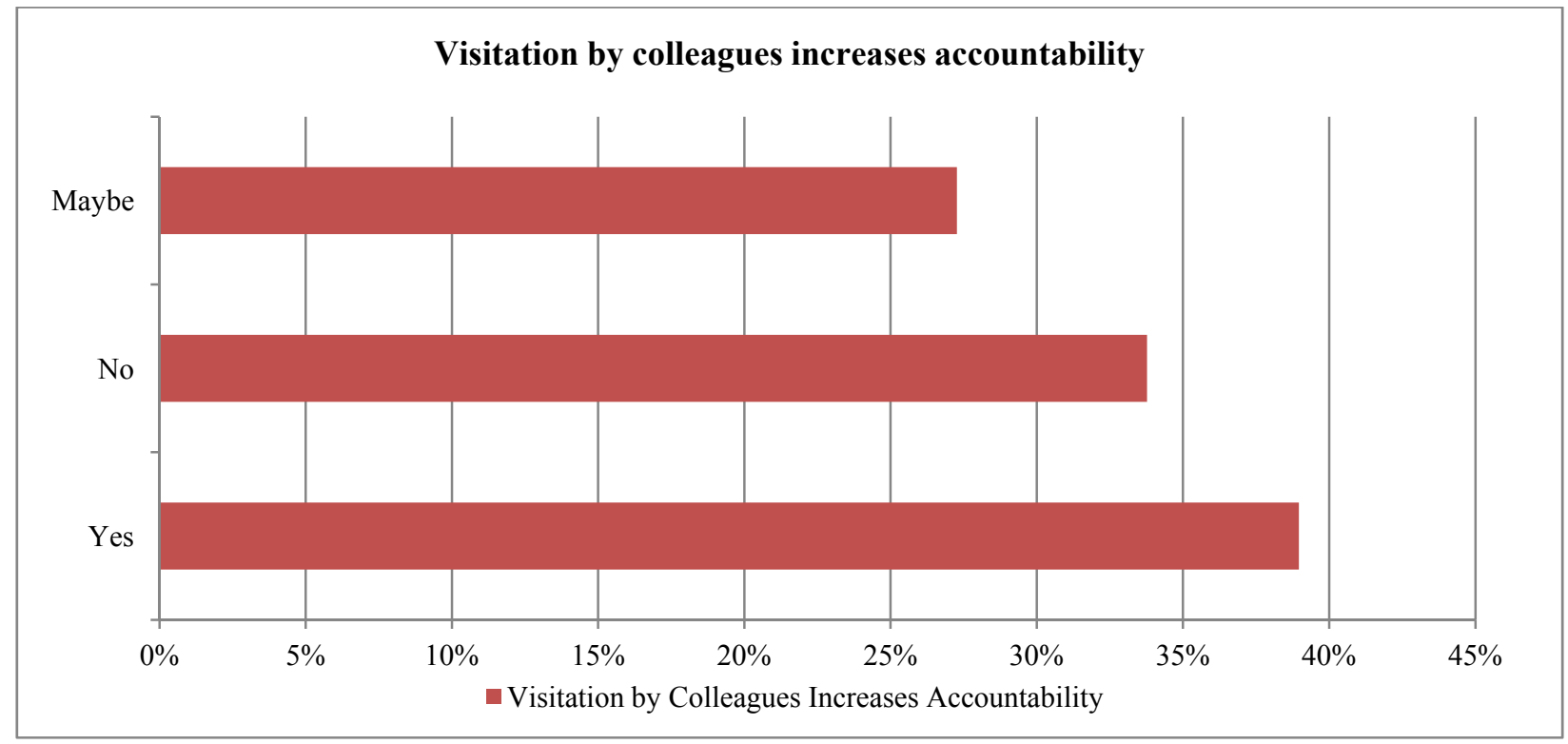

Figure 4. Visitation by colleagues increases accountability. 
The respondents indicated that they viewed peer-observation as facilitating quality programs that supported instructors' development of skills, knowledge, and positive attitudes about teaching. In this question, those who supported the above notion were $50 \%$ while those who did not agree were $22.37 \%$. The remaining $28.95 \%$ were not sure (see Table 5).

Table 5

Visitation by Colleagues Facilitates Quality Programs

\begin{tabular}{lll}
\hline Visitation facilitates quality programs & Number of respondents & Percentage (\%) \\
\hline Yes & 38 & 50 \\
No & 17 & 22.37 \\
Maybe & 22 & 28.95 \\
Total & 77 & 100 \\
\hline
\end{tabular}

The survey also asked the respondents on whether they believed that classroom visitations by colleagues encouraged instructors to identify strategies that promoted students' success. The results revealed that $44.16 \%$ agreed that indeed peer-observation led to better strategies that promoted students' success in their learning process of EFL. Figure 5 below shows the results:

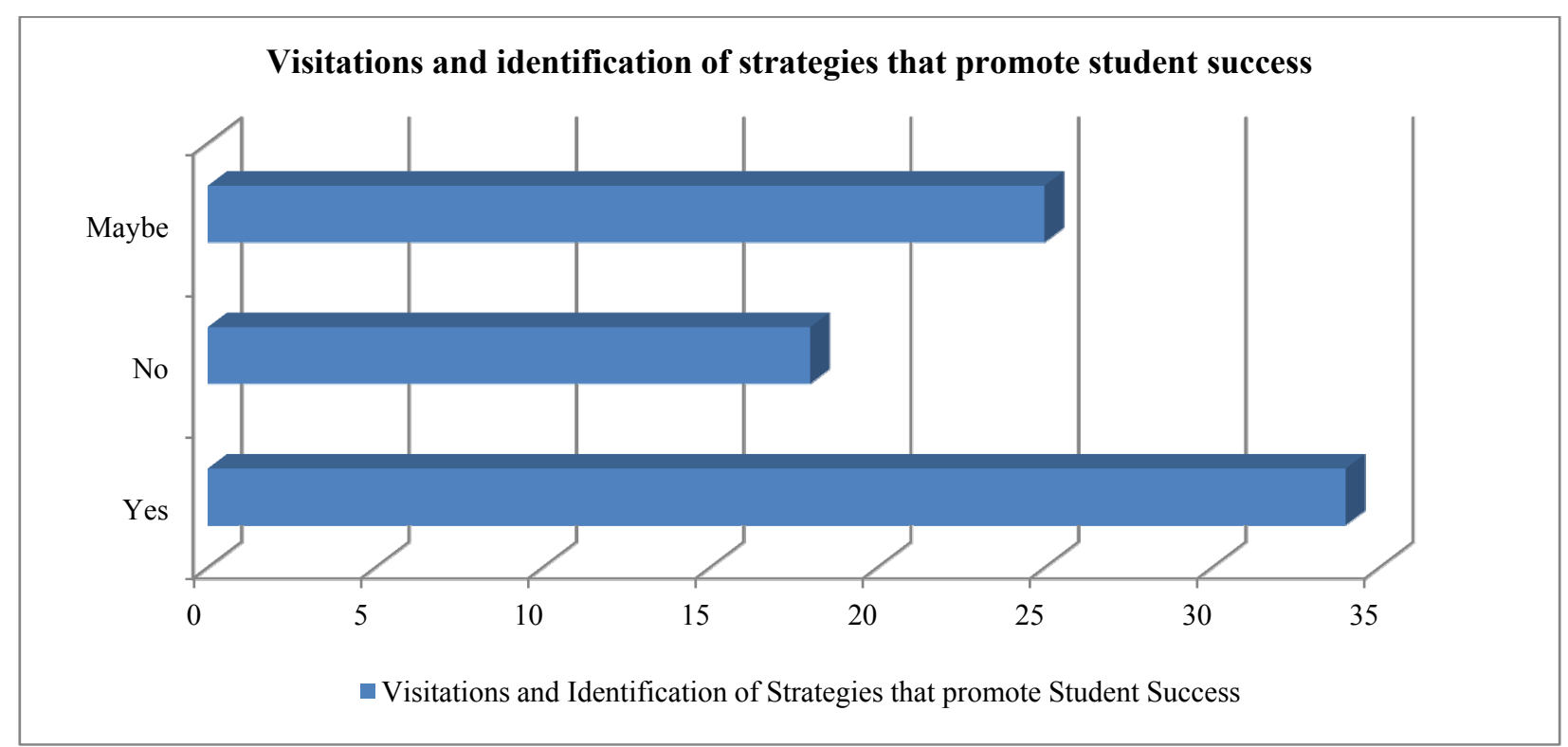

Figure 5. Visitation leads to identification of strategies that promote students' success.

The survey results also revealed a correlation between visitation by colleagues and the promotion of teaching strengths. In other words, the research showed that 49 out of 77 respondents believed that visitation by colleagues promoted teaching strengths, thus, leading to better learning outcomes for students. Figure 6 below shows the results of the survey question.

The survey also revealed that respondents viewed visitations by colleagues as helping instructors to identify new or different teaching techniques that led to better student learning. The findings indicated that those who supported the above opinion were $50 \%$ as compared to only $14.47 \%$ of those who did not share the same opinion. However, a large percentage of respondents at $35.53 \%$ were not sure of whether the visitations had influence on the identification of teaching techniques or not. Table 6 represents the results of the survey. 


\section{Visitation improves teaching strengths}

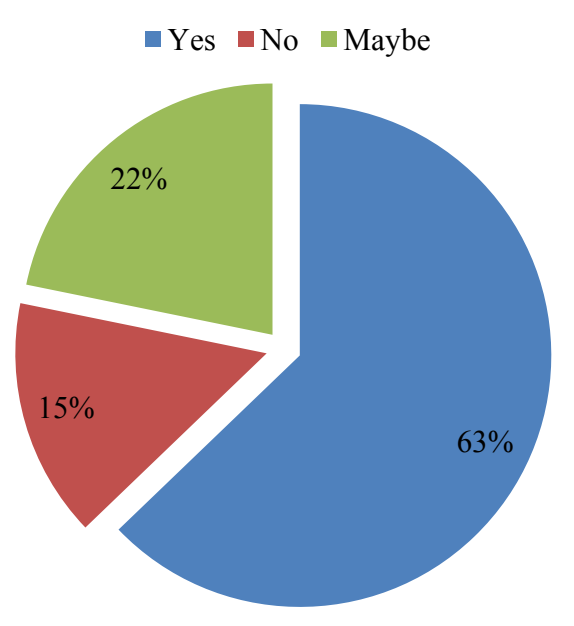

Figure 6. Visitation improves teaching strengths.

Table 6

Visitation Leads to New Teaching Techniques

\begin{tabular}{lll}
\hline Visitation leads to & Number of respondents & Percentage (\%) \\
new teaching techniques & 38 & 50 \\
Yes & 11 & 14.47 \\
No & 27 & 35.53 \\
Maybe & 76 & 100 \\
Total & & \\
\hline
\end{tabular}

On whether classroom visitations prompted teachers to revise courses or curriculum, the majority of the respondents at $36.84 \%$ did not believe that such visitations influenced a teacher's decision to revise courses/curriculum. However, $32.89 \%$ were not sure while the remaining $30.26 \%$ believed that visitations in the classroom setting by colleagues influenced the decision to revise courses (see Figure 7).

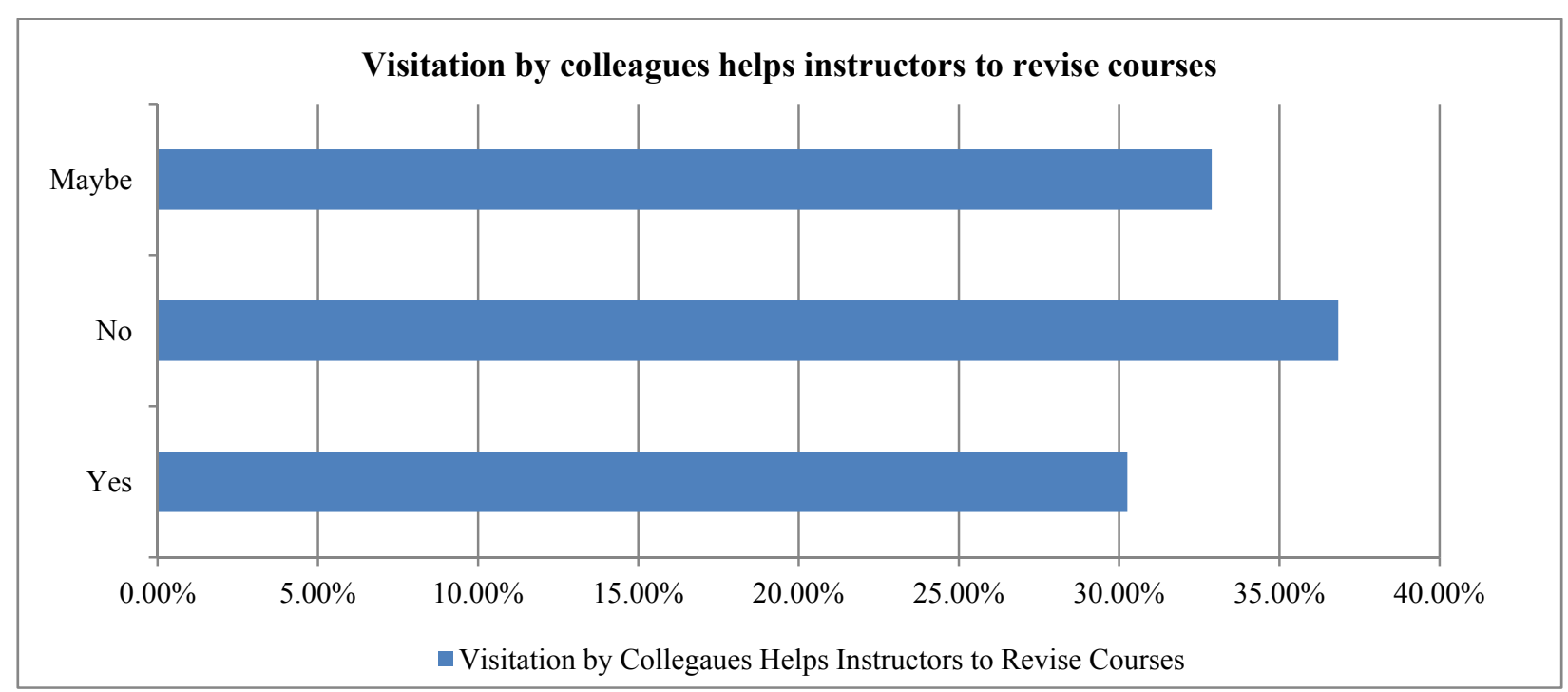

Figure 7. Visitation by colleagues helps instructors to revise courses. 
In line with the above findings, the study further revealed that the respondents believed that visitations were important in guiding teachers to maintain updated course syllabi, plans, and objectives.

It was also revealed that teachers viewed visitation by colleagues as important in assisting in the process of recruitment, selection, orientation, and evaluation of instructors (see Table 7).

Table 7

Visitation Helps in Recruitment, Selection, Orientation, and Evaluation of Instructors

\begin{tabular}{lll}
\hline $\begin{array}{l}\text { Visitation helps in recruitment, selection, } \\
\text { orientation, and evaluation of instructors }\end{array}$ & Number of respondents & Percentage (\%) \\
\hline Yes & 29 & 37.66 \\
No & 19 & 24.68 \\
Maybe & 29 & 37.66 \\
Total & 77 & 100 \\
\hline
\end{tabular}

The analysis of the survey questions showed that the respondents were divided on whether visitation had an influence on scheduling of lessons. About $40.3 \%$ of the respondents were not sure while $38.96 \%$ were sure that visitation influenced preparation of schedules. The remaining $22.08 \%$ opposed the notion that visitations assisted in the preparation of schedules.

The survey analysis showed that respondents believed that visitations influenced positive and cooperative relationships with colleagues (see Table 8).

Table 8

Visitation Influences Cooperative Relationships

\begin{tabular}{lll}
\hline Visitation influences & Number of respondents & Percentage (\%) \\
cooperative relationships & 30 & 39.47 \\
Yes & 21 & 27.63 \\
No & 25 & 32.89 \\
Maybe & 76 & 100 \\
Total & & \\
\hline
\end{tabular}

The number of respondents who believed that visitations by colleagues influenced teachers' selection of supplemental instructional materials was only 28 out of the 76 who responded to the question. Majority of the respondents at 29 out of 76 were not sure about the effect of visitation on the selection of supplemental instructional materials. The remaining 19 out of 76 disagreed with the premise implied by the survey question.

On whether visitation affected the teachers' academic freedom, the following results were revealed (see Figure 8):

Concerning whether the class would remain typical of the teachers' normal operations during observation, $38.16 \%$ of the respondents believed that the observation would not change anything. However, $28.95 \%$ of them felt that their classes would not remain normal during observation. The rest of the respondents were unsure of the outcomes of observations in the class environment.

The survey revealed that majority of the respondents at $36 \%$ did not believe that the visitations by colleagues would enhance academic freedom, as teachers will have improved teaching skills through their participation in the peer-observation process. Another $34.67 \%$ of the respondents were not sure while only $29.33 \%$ had the opinion that they would achieve more academic freedom. 


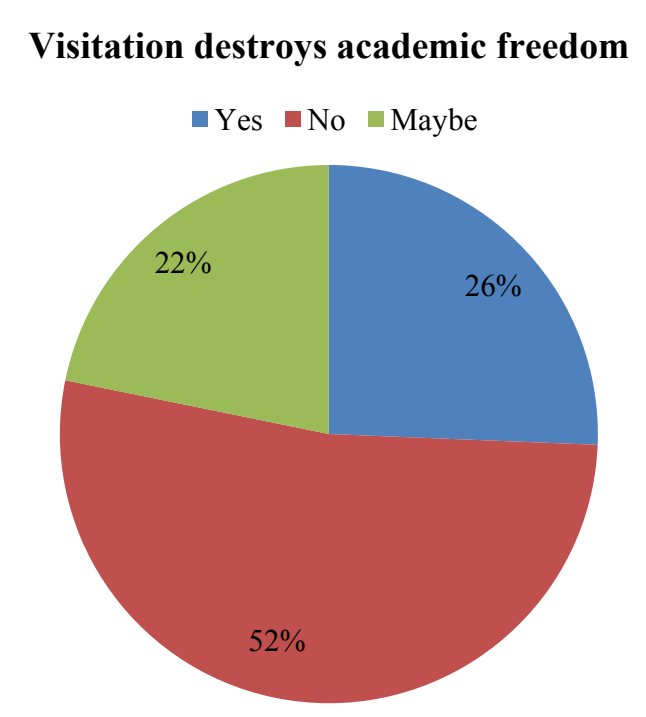

Figure 8. Visitation and academic freedom.

The study questioned the respondents on their opinion on whether they felt that peer-observation was biased. The results revealed that an overwhelming $47.30 \%$ of the respondents were not sure whether the peer-observation could be biased. Another $31.08 \%$ were sure that the peer-observation was not biased while $21.62 \%$ felt that peer-observation was biased. Figure 9 below summarizes the findings of the survey question.

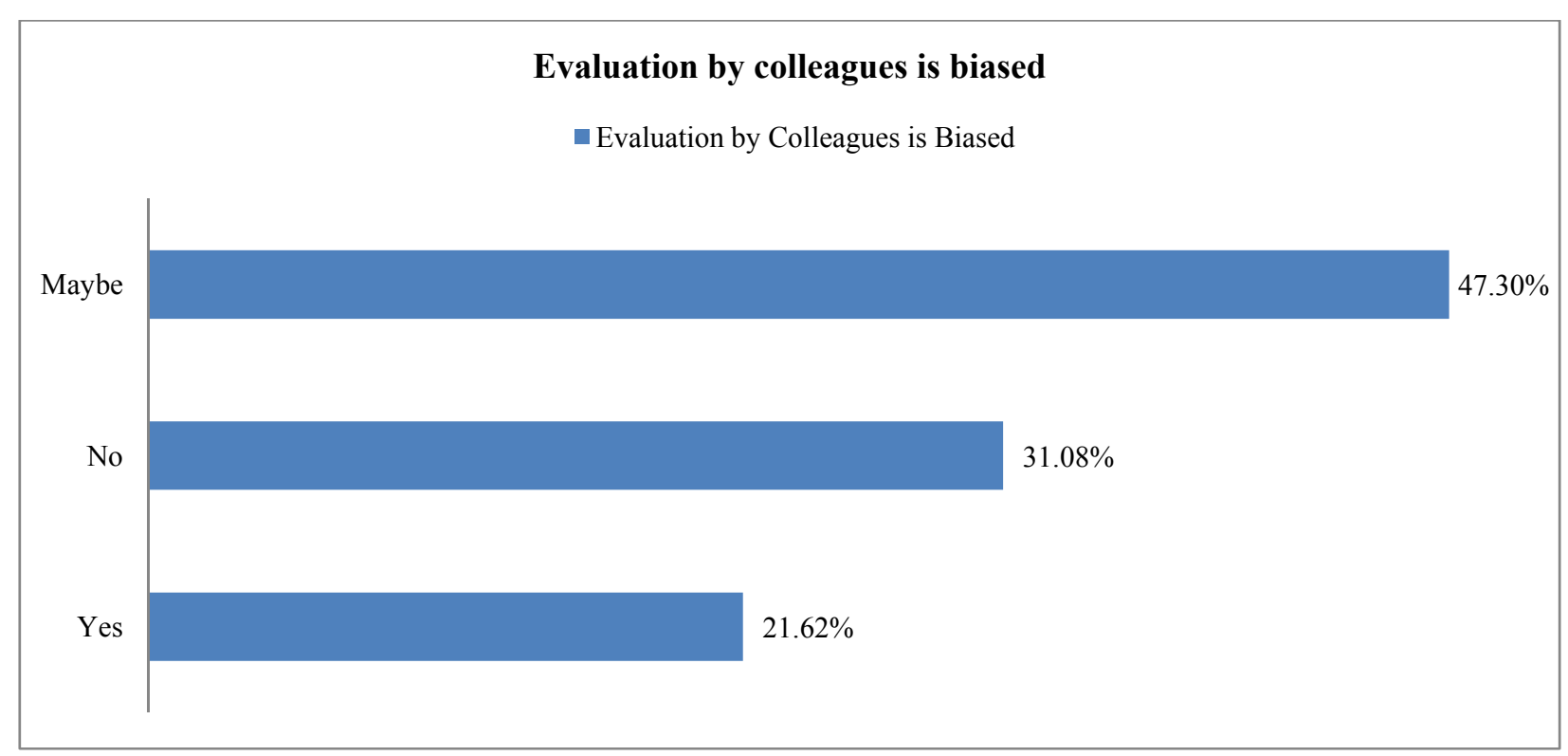

Figure 9. Evaluation by colleagues is biased.

Majority of the respondents at $43.42 \%$ pointed out that they felt that the presence of an evaluator in the classroom negatively affected the attention of students. About $37 \%$ were not sure while the remaining $21.05 \%$ were of the opinion that the presence of an evaluator did not affect the students' attention.

Another survey question revealed that classroom visitations by colleagues led the teacher to undertake self-assessments. In this case, $56.58 \%$ of the respondents agreed that teachers had higher tendency of 
self-assessment when expecting and after visitations. Only $21.05 \%$ of them were opposed to the above notion while the remaining $22.37 \%$ were unsure.

Respondents reported missed answers regarding whether they felt under rigorous review during peer-observations. Approximately $48 \%$ of the respondents were not sure while $32 \%$ of them felt that they were under rigorous review during the visitations. The other $21.33 \%$ felt that the evaluation process did not put them under rigorous review.

On whether the teachers would be involved or contribute to the development of a program for faculty professional development through peer-observation by peers, $44.74 \%$ of the respondents said that they would be willing to contribute. About $22 \%$ pointed that they would not be willing to contribute while the remaining $32.89 \%$ were not sure whether they would contribute or not.

Concerning the question on the number of visitations by peers, an overwhelming $76.06 \%$ were of the opinion that one visit per year was adequate. Only $8.45 \%$ were sure that one visit per semester was inadequate. Those who were undecided were $15.49 \%$ (see Table 9).

Table 9

One Classroom Visit Per Year Is Adequate

\begin{tabular}{llc}
\hline One visit per year is adequate & Number of respondents & Percentage (\%) \\
\hline Yes & 54 & 76.06 \\
No & 6 & 8.45 \\
Maybe & 11 & 15.49 \\
Total & 71 & 100 \\
\hline
\end{tabular}

The respondents were asked to provide their opinions on whether it was important for the peer evaluators to be familiar with the course content and objectives. The respondents overwhelmingly at $93.06 \%$ felt that it was necessary for the evaluator to be familiar with the course content and objectives. Only $2.78 \%$ did not feel the same while $4.17 \%$ were undecided (see Figure 10 ).

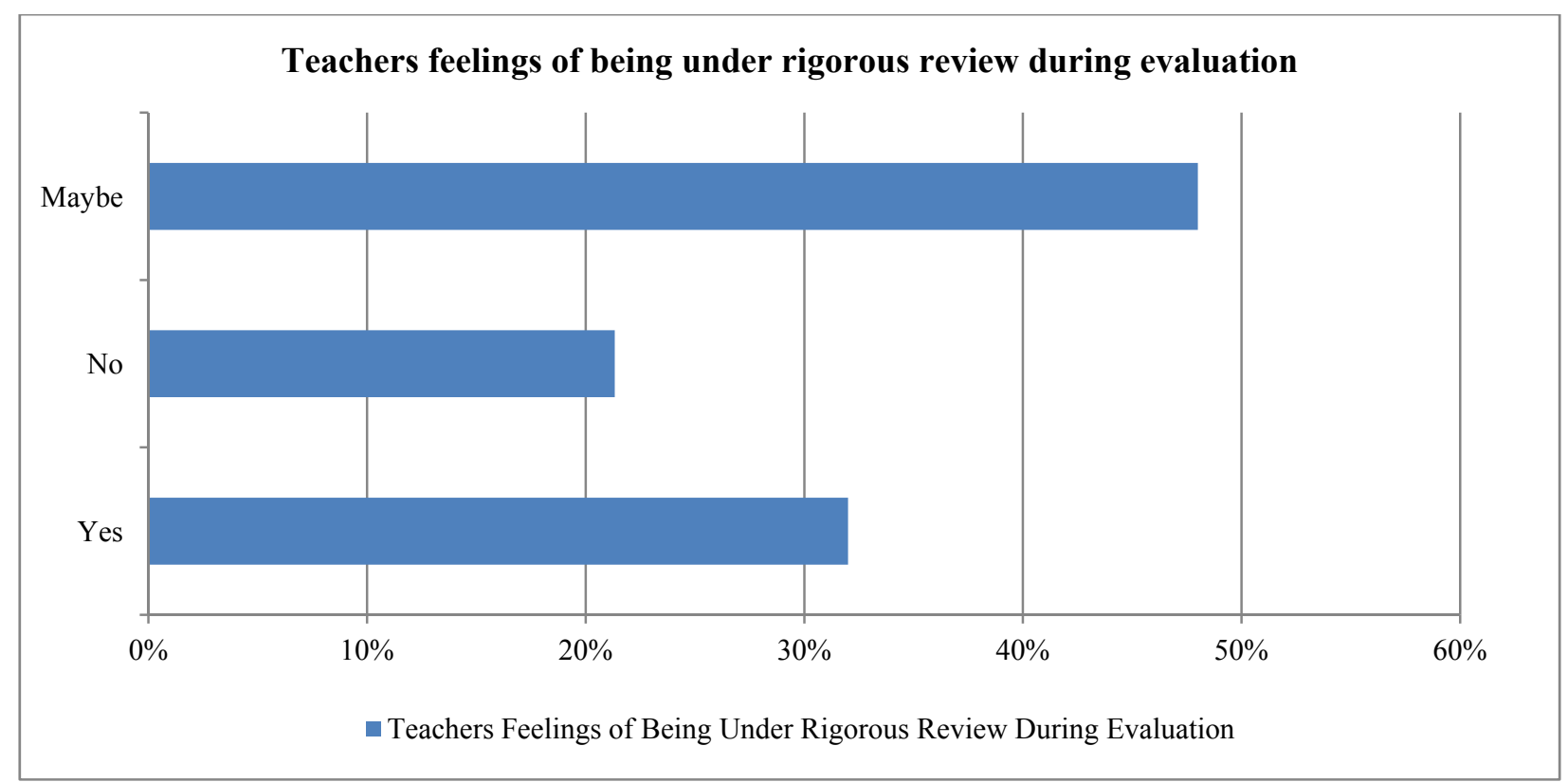

Figure 10. Teachers' feelings of being under rigorous review during evaluation. 
Table 10

Evaluator Should Understand the Course Content and Objectives

\begin{tabular}{lcc}
\hline Evaluator should understand the & Number of respondents & Percentage (\%) \\
course content and objectives & 67 & 76.06 \\
Yes & 2 & 8.45 \\
No & 3 & 15.49 \\
Maybe & 72 & 100 \\
Total & & \\
\hline
\end{tabular}

The survey further revealed that the respondents agreed that the reviewer should have an understanding of the course environment, which includes course materials, assignments, quizzes, and examinations among other relevant materials. The survey shows that $72.22 \%$ of the respondents supported the notion while $15.28 \%$ did not believe the reviewer needed to understand the course materials. The other $12.50 \%$ were undecided on the importance of an understanding of the course environment by the reviewer. Figure 11 shows the outcomes of the question from the survey.

In the question regarding a pre- and post- observation meeting, the respondents note its importance in discussing important evaluation points. Of the 72 respondents who answered the question, $88.89 \%$ supported the importance of a pre- and post- observation meeting. Only $1.39 \%$ of the respondents did not recognize the importance of such a convention. The remaining $11.11 \%$ were undecided on the importance of such a conference.

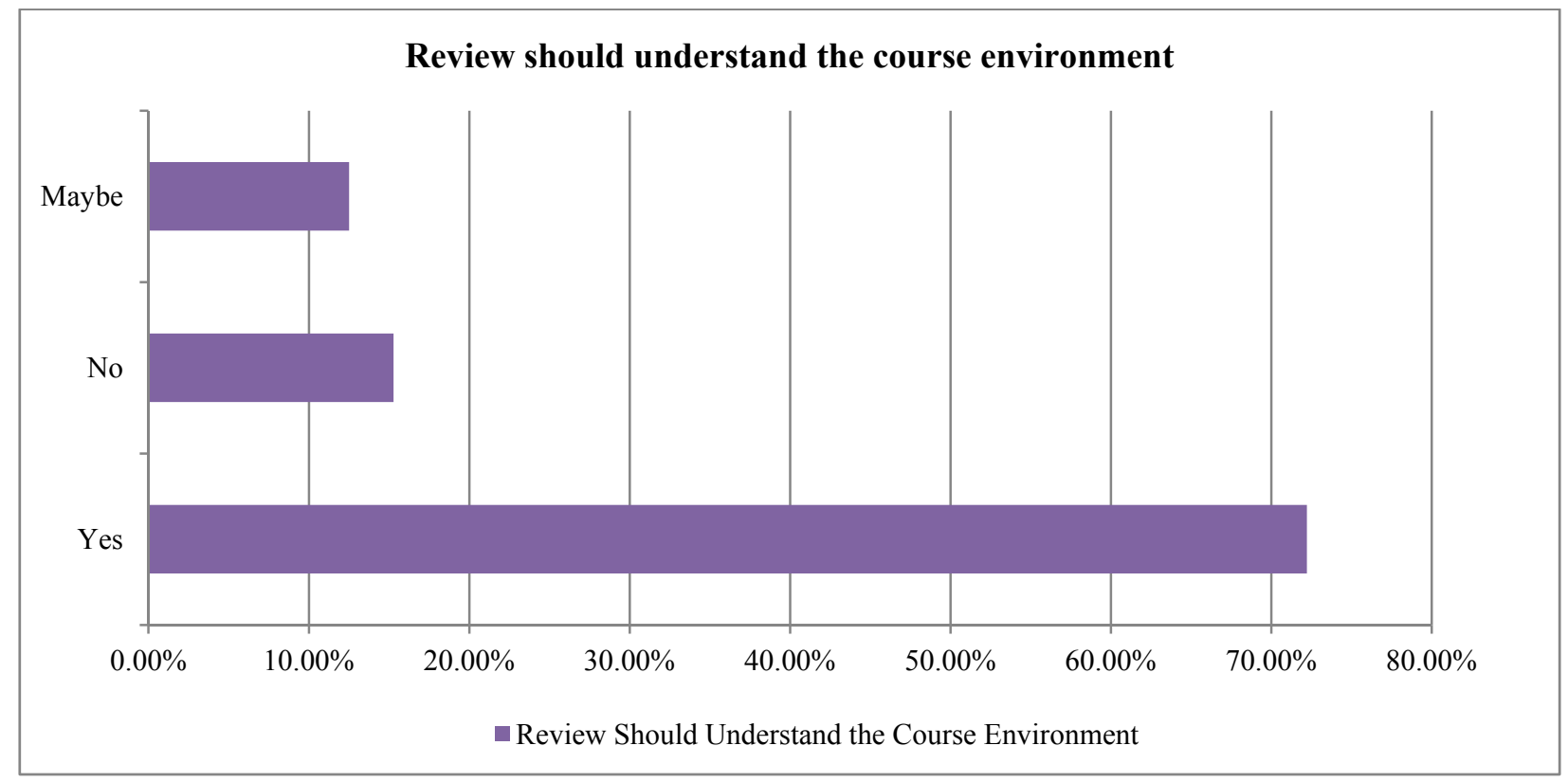

Figure 11. Review should understand the course environment.

The respondents noted the importance of consultation between the evaluator and the instructor in the selection of the class to be observed. About $85 \%$ of the respondents supported the relevance of consultation between the instructor and the evaluator in the selection of the class to be evaluated. The remaining $4.17 \%$ of the respondents did not support the consultation between the instructor and the evaluator while the remaining $11.11 \%$ were unsure. 
The survey questions and respective responses also revealed a consensus that direct observation of the instructor by colleagues who are most familiar with teaching and learning was the best evaluation of teaching effectiveness. Figure 12 summarizes the findings of the research.

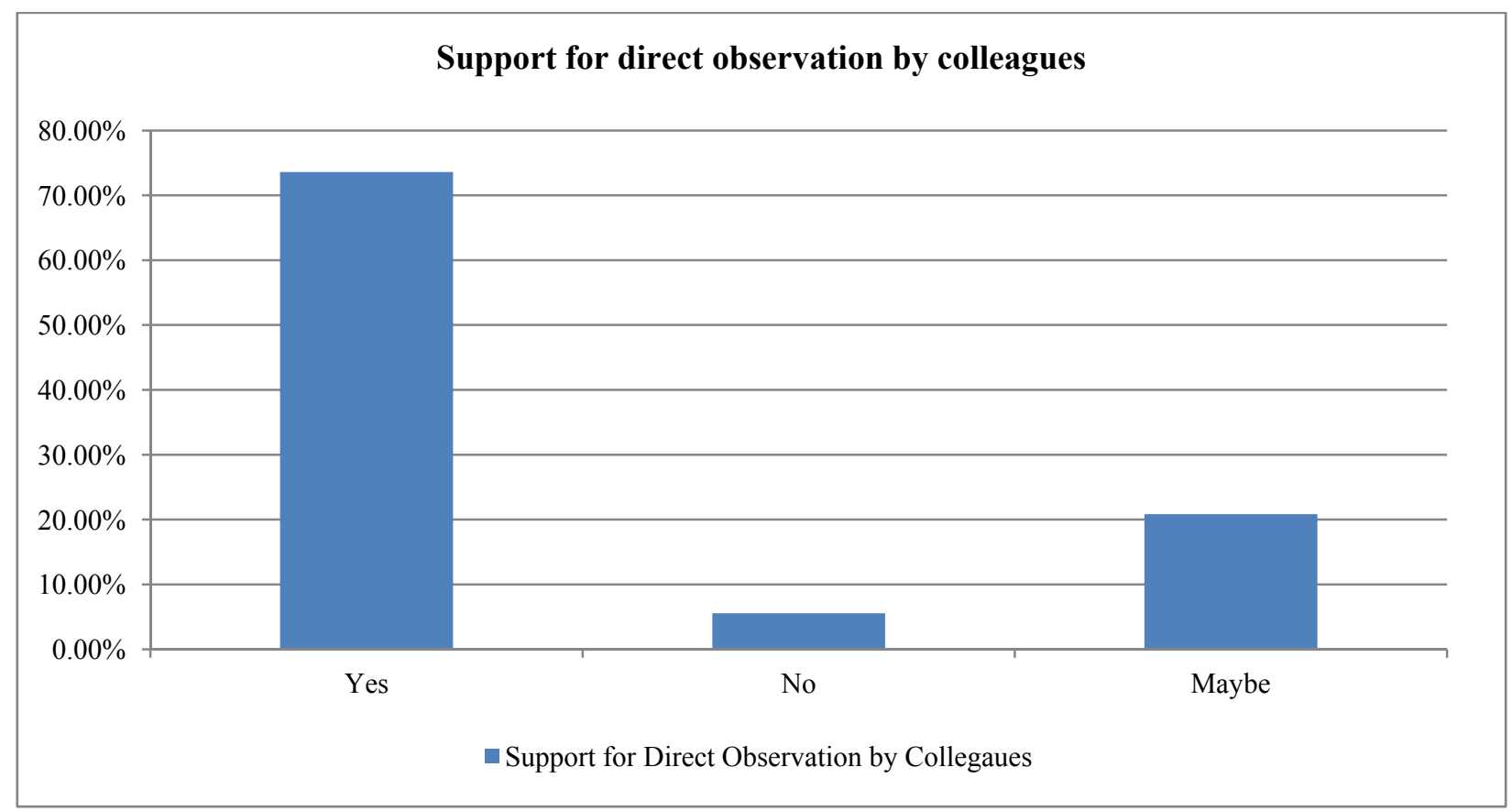

Figure 12. Support for direct observation by colleagues.

The respondents further argued that it was important for the evaluator to observe the teaching practices of the instructor such as mastery and course organization. About $76.4 \%$ of the respondents supported the premise of the question while $4.17 \%$ did not. The remaining $19.44 \%$ were undecided.

The respondents were prompted to respond on whether they felt that observing appropriateness of course objectives, effectiveness of course materials, and the involvement of students in achieving the desire course outcomes was important. Of the responses, $77.78 \%$ respondents indicated the importance of such observation. Only $2.78 \%$ were against it while $19.44 \%$ were not sure (see Table 11 ).

\section{Table 11}

Importance of Observing Appropriateness of Course Objectives

\begin{tabular}{lcc}
\hline Importance of observing & Number of respondents & Percentage (\%) \\
appropriateness of course objectives & 56 & 77.78 \\
Yes & 2 & 2.78 \\
No & 14 & 19.44 \\
Maybe & 72 & 100 \\
Total & & \\
\hline
\end{tabular}

Another question sought the response of the participants on their views concerning the involvement of junior and senior instructors in the evaluation process. The responses showed that the participants agreed that both the junior and senior instructors would benefit from the colleagues visitations (see Table 12). 
Table 12

Evaluation of Both Junior and Senior Instructors

\begin{tabular}{lll}
\hline Evaluation of both junior and & Number of respondents & Percentage (\%) \\
senior instructors & 37 & 52.86 \\
\hline Yes & 16 & 22.86 \\
No & 17 & 24.29 \\
Maybe & 70 & 100 \\
Total & & \\
\hline
\end{tabular}

The survey noted that in the current education system, visitations are majorly undertaken upon the request of an instructor, as opposed to being part of the quality assurance approaches in institutions of higher learning.

Lastly, respondents expressed different opinions on whether a few classroom visits by one colleague could produce a reliable judgment. About $46 \%$ of the respondents felt that few visitations by one colleague would not produce reliable judgment. Only $8.33 \%$ of the respondents felt that few visitations would produce the needed outcomes. The other respondents representing $45.83 \%$ were not sure whether few visitations by one associate were adequate or not. Figure 13 represents the information on the responses of the participants regarding this question.

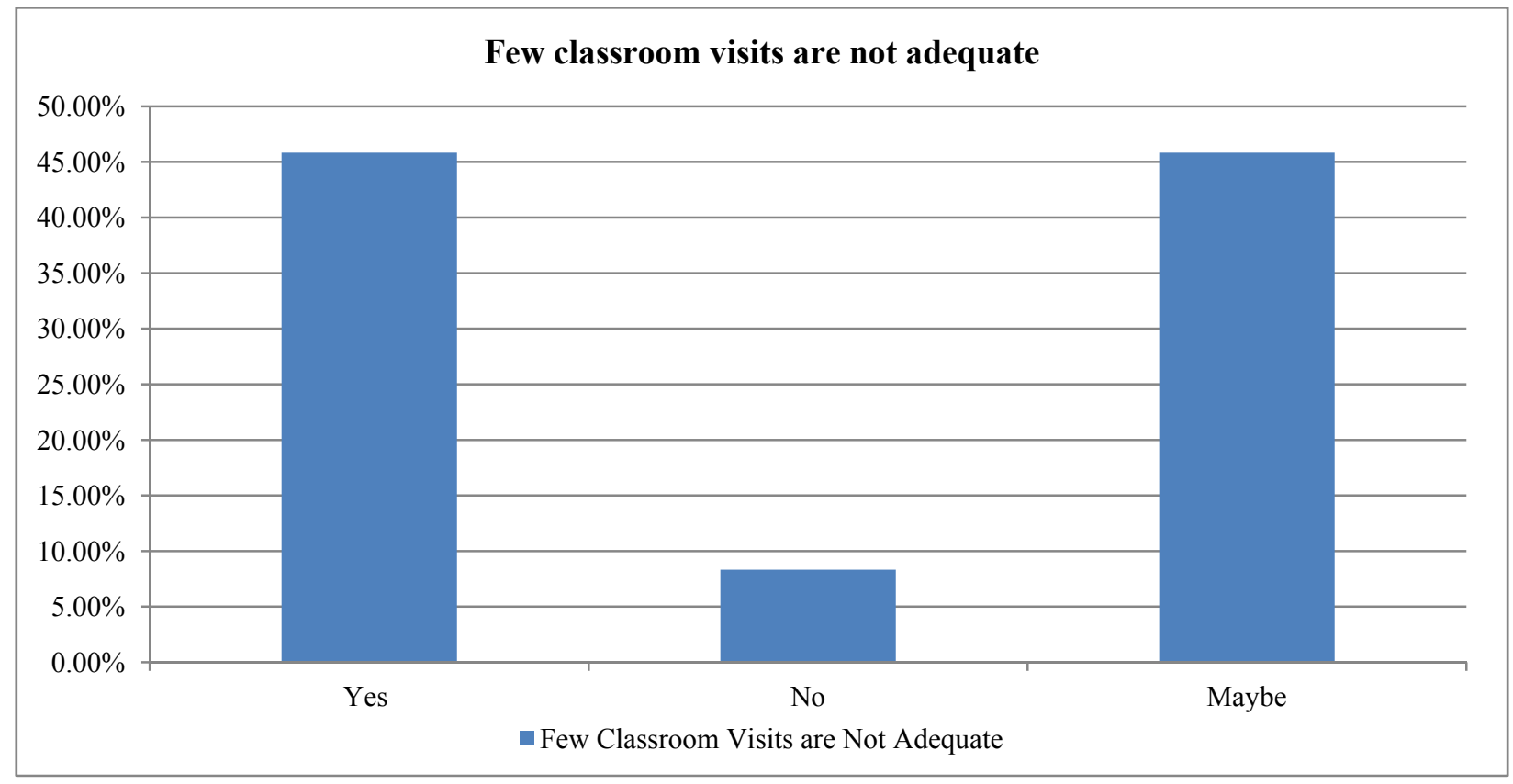

Figure 13. Few classroom visits are inadequate to make a judgment.

\section{Findings and Recommendations}

\section{Findings}

The findings of the research provide important insights into the effectiveness and support for peer-observations in the teaching of English in Higher Institutions of Education in Saudi Arabia. Firstly, from the above analysis, it is evident that one of the key challenges in the sector is the availability of qualified teachers of English in the country. The high number of teachers with a bachelor's degree teaching English in higher education is a cause of worry and a major indicator of the challenges facing the teaching and learning of 
English. Only a small number of teachers have a masters or a doctorate degree, which are the important qualifications when teaching English or any other subject in universities. The findings also reveal the support and desire for teachers to be engaged in peer-observation processes towards improvement of the quality of training that they offer to students. However, several concerns from the study require to be addressed to ensure that the application of peer-observation is effective as presented in the recommendations.

\section{Recommendations}

The following are the recommendations that should be considered in the adoption of peer-observation in teaching of English in Saudi Arabia's institutions of higher learning. Firstly, there is the need for training among teachers to be undertaken to ensure that that they have the necessary skills relating to peer-observation of learning and teaching. Secondly, there is the need for training to address some of the raised concerns, which can derail the success of the peer-observation approaches. There is also the need for close cooperation between accreditation institutions and individual institutions in promoting the adoption of POLT approaches successfully. The involvement and support of top managements of each institution and respective English teaching department is essential in the success of the program.

\section{Conclusions}

The low level of English proficiency among students in Saudi Arabia has been caused by many factors, including the teacher-centered approach, which does not support active involvement of students in the learning process. Although quality assurance programs have been implemented in the country, the outcomes for English have not improved. It is for this reason that the use of POLT is an important quality assurance and evaluation approach that can greatly influence students' learning outcomes. The research has revealed that although teachers have some concerns on the application of the concept and its approaches, there is an overwhelming support for the approach in higher education learning of English. The application of the POLT requires the cooperation of relevant authorities and institutions of higher to ensure the best outcomes for the teachers and students in the teaching and the learning approaches.

\section{References}

Al Shannag, Q., Tairab, H., Dodeen, H., \& Abdel-Fattah, F. (2013). Linking teachers' quality and student achievement in the Kingdom of Saudi Arabia and Singapore: The impact of teachers' background variables on student achievement. Journal of Baltic Science Education, 12(5), 652-665.

Al-Mekhlafi, A. M., \& Nagaratnam, R. P. (2011). Difficulties in teaching and learning grammar in an EFL context. Online Submission, 4(2), 69-92.

Alrashidi, O., \& Phan, H. (2015). Education context and English teaching and learning in the Kingdom of Saudi Arabia: An overview. English Language Teaching, 8(5), 33-44.

Altan, M. Z. (2006). Preparation of foreign language teachers in Turkey: A challenge for the 21st century. Dil Dergisi, 134(1), 49-54.

Arnold, E. (2006). Assessing the quality of mentoring: Sinking or learning to swim? ELT Journal, 60(2), 117-124.

Bell, A., \& Mladenovic, R. (2008). The benefits of peer observation of teaching for tutor development. Higher Education, 55(6), 735-752.

Berardo, S. A. (2006). The use of authentic materials in the teaching of reading. The Reading Matrix, 6(2), 60-69.

Brown, S. (2011). Bringing about positive change in the higher education student experience: A case study. Quality Assurance in Education, 19(3), 195-207.

Chong, S., \& Cheah, H. (2009). A values, skills and knowledge framework for initial teacher preparation programs. Australian Journal of Teacher Education, 34(3), 1-17. 
Coskun, A., \& Daloglu, A. (2010). Evaluating an English language teacher education program through peacock's model. Australian Journal of Teacher Education, 35(6), 24-42.

Darandari, E., Al-Qahtani, S. A., Allen, I. D., Al-Yafi, W. A., Al-Sudairi, A. A., \& Catapang, J. (2009). The quality assurance system for post-secondary education in Saudi Arabia: A comprehensive, developmental and unified approach. Quality in Higher Education, 15(1), 39-50.

Darling-Hammond, L. (2006). Assessing teacher education the usefulness of multiple measures for assessing program outcomes. Journal of Teacher Education, 57(2), 120-138.

Darling-Hammond, L. (2008). Teacher learning that supports student learning. Teaching for Intelligence, 2(1), 91-100.

Darling-Hammond, L. (2010). Teacher education and the American future. Journal of Teacher Education, 61(1-2), 35-47.

Darling-Hammond, L., Wei, R. C., Andree, A., Richardson, N., \& Orphanos, S. (2009). Professional learning in the learning profession. Washington, D.C.: National Staff Development Council.

Donnelly, R. (2007). Perceived impact of peer observation of teaching in higher education. International Journal of Teaching and Learning in Higher Education, 19(2), 117-129.

Fareh, S. (2010). Challenges of teaching English in the Arab world: Why can't EFL programs deliver as expected? Procedia-Social and Behavioral Sciences, 2(2), 3600-3604.

Harford, J., \& MacRuairc, G. (2008). Engaging student teachers in meaningful reflective practice. Teaching and Teacher Education, 24(7), 1884-1892.

Harvey, L., \& Stensaker, B. (2008). Quality culture: Understandings, boundaries and linkages. European Journal of Education, 43(4), 427-442.

Kohut, G. F., Burnap, C., \& Yon, M. G. (2007). Peer observation of teaching: Perceptions of the observer and the observed. College Teaching, 55(1), 19-25.

Light, G., Calkins, S., \& Cox, R. (2009). Learning and teaching in higher education: The reflective professional. London, U.K.: Sage Publishers.

Liton, H. A. (2013). EFL teachers' perceptions, evaluations, and expectations about English language courses as EFL in Saudi universities. International Journal of Instruction, 6(2), 19-34.

Martin, D., \& Loomis, K. (2013). Building teachers: A constructivist approach to introducing education. London, U.K.: Cengage Learning.

Marzano, R. J., \& Toth, M. D. (2013). Teacher evaluation that makes a difference: A new model for teacher growth and student achievement. Alexandria, V.A.: Association for Supervision and Curriculum Development.

Minott, M. A., \& Young, A. E. (2009). The benefits of employing a hybrid evaluation approach, enacted through evaluation survey and reflective journaling in teacher education in the Cayman Islands. Australian Journal of Teacher Education, 34(4), $16-26$.

Moskovsky, C., \& Alrabai, F. (2009). Intrinsic motivation in Saudi learners of English as a foreign language. The Open Applied Linguistics Journal, 2(1), 1-10.

Peacock, M. (2009). The evaluation of foreign-language-teacher education programs. Language Teaching Research, 13(3), 259-278.

Price, J., Roth, M., Shott, S., \& Andrews, S. (2012). Preparing pre-service teachers: A faculty review strategy. Society for Information Technology \& Teacher Education International Conference, 2(1), 2068-2076.

Ross, J. A., \& Bruce, C. D. (2007). Teacher self-assessment: A mechanism for facilitating professional growth. Teaching and Teacher Education, 23(2), 146-159.

Shortland, S. (2007). Participation, justice, and trust within developmental peer observation of teaching: A model and research agenda. The International Journal of Management Education, 6(1), 27-37. 